\title{
Sustainability of Natural Attenuation of Nitrate in Agricultural Aquifers
}

ncreased concentrations of
nitrate in groundwater in agri-
cultural areas, coinciding with
increased use of chemical and
organic fertilizers, have raised
concern because of risks to envi-
ronmental and human health. At
some sites, these problems are
mitigated by natural attenuation
of nitrate as a result of microbially
mediated reactions. Results from
U.S. Geological Survey (USGS)
research under the National Water-
Quality Assessment (NAWOA)
program show that reactions of
dissolved nitrate with solid aquifer
minerals and organic carbon help
lower nitrate concentrations in
groundwater beneath agricultural
fields. However, increased fluxes
of nitrate cause ongoing depletion
of the finite pool of solid reactants.
Consumption of the solid reactants
diminishes the capacity of the
aquifer to remove nitrate, calling
into question the long-term sustain-
ability of these natural attenuation
processes.

Increased use of chemical and organic fertilizers in agricultural areas (fig. 1) over the past 50 years has coincided with increased nutrient concentrations in groundwater (see, for example, Böhlke, 2002). Today nitrate $\left(\mathrm{NO}_{3}{ }^{-}\right)$is one of the most abundant groundwater contaminants in the United States (Nolan and Stoner, 2000). This is cause for concern because elevated $\mathrm{NO}_{3}{ }^{-}$concentrations have been associated with human health risks (World Health Organization, 2004), and when $\mathrm{NO}_{3}$--laden groundwater discharges to surface waters, it contributes to eutrophication (Howarth and Marino, 2006).

One important factor determining the extent and duration of $\mathrm{NO}_{3}{ }^{-}$contamination

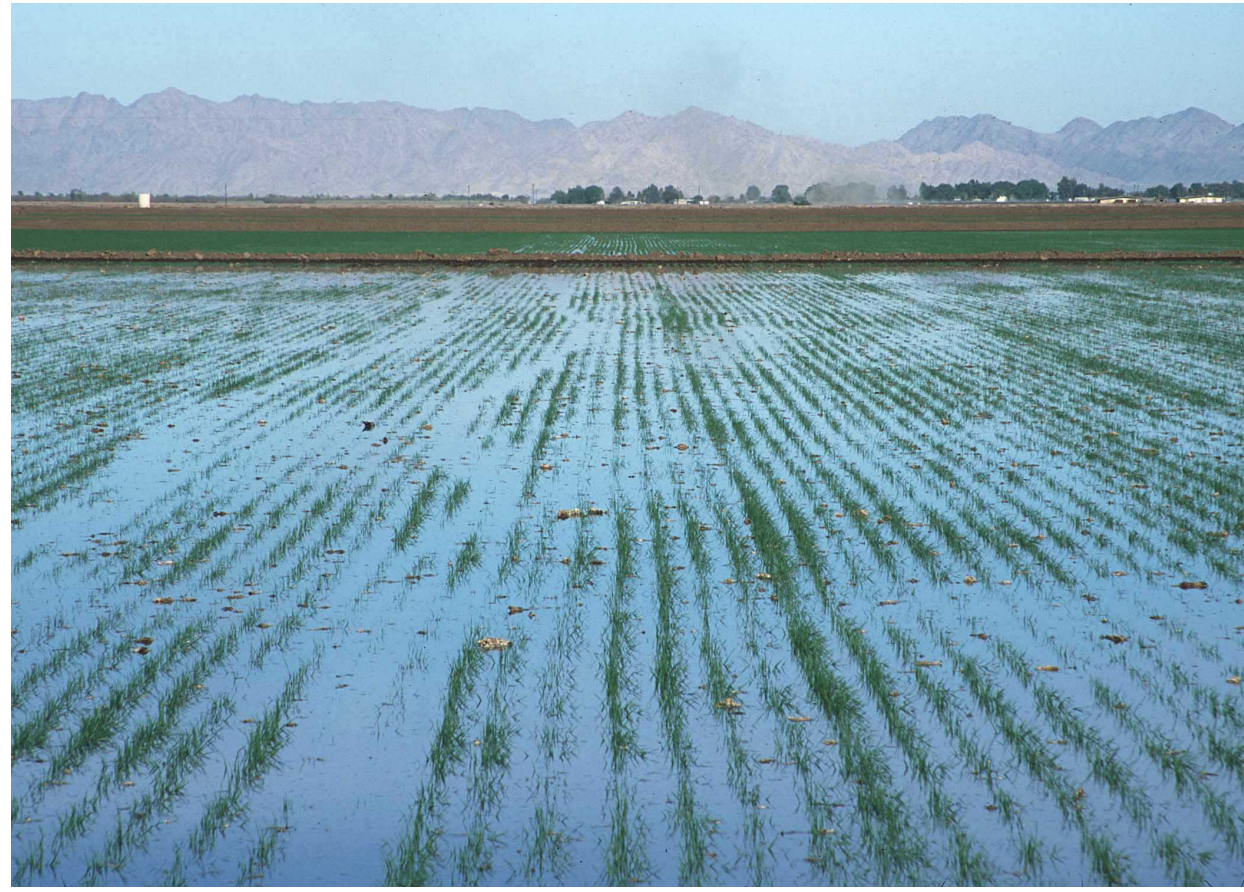

Figure 1. Agricultural uses of water and fertilizers affect the chemistry of underlying aquifers. In this photo, irrigation water percolates into a wheat field in Yuba, Arizona. Photo by Jeff Vanuga , U.S. Department of Agriculture Natural Resources Conservation Service.

is denitrification, a type of reduction-oxidation or "redox" reaction. These reactions involve the chemical transfer of electrons from reduced compounds ("reductants") to electron-accepting compounds ("oxidants"). A commonly observed example in everyday life is the corrosion of exposed iron. In the presence of water, electrons pass from the reductant (iron) to the oxidant (oxygen gas) to form rust consisting of iron oxides, hydroxides, and oxyhydroxides. Microorganisms facilitate many redox reactions such as denitrification. In groundwater, electron transfer from organic or inorganic reductants to $\mathrm{NO}_{3}{ }^{-}$generates energy for denitrifying microorganisms. The denitrification reaction creates $\mathrm{N}_{2}$, a harmless gas, and consumes $\mathrm{NO}_{3}{ }^{-}$, helping to prevent or reverse groundwater contamination by this compound.

Figure 2 shows a schematic of redox processes important to the fate of groundwater $\mathrm{NO}_{3}{ }^{-}$. Some reactants required for denitrification arrive in groundwater as dissolved solutes originating near the land surface and recharging through the unsaturated zone to the groundwater table. Others are released from the solid phase, meaning they are derived from aquifer rocks or sediments. Dissolved $\mathrm{O}_{2}$ and $\mathrm{NO}_{3}{ }^{-}$infiltrating from the surface are important oxidants, while solid-phase organic carbon (OC), solid minerals with iron ( $\mathrm{Fe}$ ) and sulfur (S), and dissolved OC (DOC) are important reductants. The subsurface microorganisms that mediate redox reactions can be categorized as aerobic (requiring the presence of $\mathrm{O}_{2}$ ) or anaerobic (thriving in the absence of $\mathrm{O}_{2}$ ). Aerobic microorganisms use dissolved $\mathrm{O}_{2}$ to oxidize available reductants. When dissolved $\mathrm{O}_{2}$ is exhausted, anaerobic microbes use $\mathrm{NO}_{3}{ }^{-}$to oxidize available reductants (denitrification). Understanding the source and availability of reductants used by microbes for denitrification is central to predicting the extent to which this natural attenuation process can help control $\mathrm{NO}_{3}{ }^{-}$contamination in groundwater.

The U.S. Geological Survey (USGS) has made groundwater $\mathrm{NO}_{3}{ }^{-}$contamination 


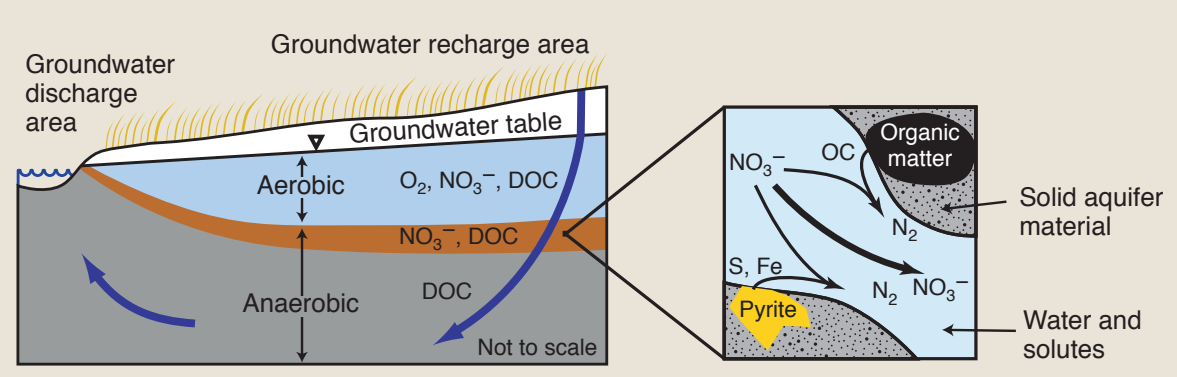

Figure 2. Schematic diagrams showing the fluxes of oxidants and reductants in an aquifer (left) and in water-filled pore-spaces between aquifer solids (right). The oxidants $\mathrm{O}_{2}$ (dissolved oxygen gas) and $\mathrm{NO}_{3}{ }^{-}$ (nitrate) percolate through the unsaturated zone to the groundwater table and into groundwater. In shallow aerobic (containing $\mathrm{O}_{2}$ ) groundwater, microorganisms consume $\mathrm{O}_{2}$ until it is depleted. In the anaerobic zone (without $\mathrm{O}_{2}$ ) microorganisms reduce $\mathrm{NO}_{3}{ }^{-}$. At four studied sites, dissolved organic carbon (DOC) passes through these aerobic and anaerobic zones without substantial changes (see fig. 5), indicating that some or all DOC originating from the land surface may be nonreactive. As shown on the right, microorganisms reduce $\mathrm{NO}_{3}{ }^{-}$using reductants such as sulfur $(\mathrm{S})$, iron (Fe), and organic forms of carbon (OC). Reactive OC can originate from solid organic matter, while $S$ and Fe can originate from minerals such as pyrite. Because of limited availability of reductants, some $\mathrm{NO}_{3}{ }^{-}$does not react and passes farther into the anaerobic zone.

in agricultural areas a focus of its National Water-Quality Assessment (NAWQA) Program because survey data show that this problem is widespread (Dubrovsky and others, 2010). The factors controlling $\mathrm{O}_{2}$ reduction and denitrification are part of a broader NAWQA study initiated in 2004 on the fate and transport of agricultural chemicals. Sites selected for intensive study were in important agricultural systems in California, Washington, Nebraska, and Maryland (fig. 3; Capel and others, 2004). As a part of this Agricultural Chemicals Team (ACT) study, critical factors were identified that affect natural attenuation of agricultural contaminants in groundwater. To characterize denitrification, ACT employed sophisticated analyses, including various stable isotopes, dissolved gases in groundwater, solid-phase mineralogy and chemistry, groundwater age-tracers, and major ion chemistry (Green and others, 2008a).

\section{Denitrification at ACT Sites}

Combined results from investigations completed at the ACT study sites show that $\mathrm{O}_{2}$ reduction and denitrification are controlled by solid phases of $\mathrm{OC}$ as well as Fe- and S-minerals in the aquifers. At these sites, reduced $\mathrm{Fe}$ and $\mathrm{S}$ are absent in recharging water, and DOC concentrations are typically too low to account for the mass of $\mathrm{O}_{2}$ and $\mathrm{NO}_{3}{ }^{-}$that has been reduced in the groundwater (fig. 4). Therefore, the observed $\mathrm{O}_{2}$ reduction and denitrification rates at these sites reflect

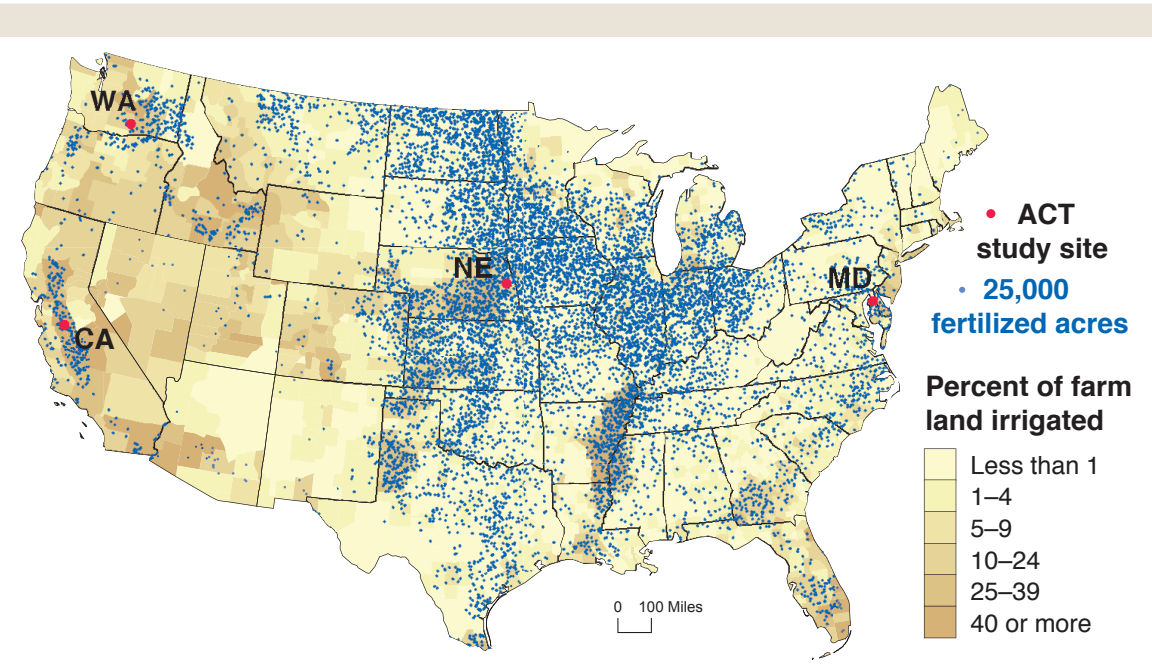

Figure 3. Irrigation and agricultural fertilization in the conterminous United States, with the locations of the four study sites in California (CA), Maryland (MD), Nebraska (NE), and Washington (WA). Each small blue dot represents 25,000 acres treated with commercial fertilizer, lime, and(or) soil conditioners. The yellow to brown color shades show the percent of irrigated land relative to total land in farms for each county (adapted from U.S. Department of Agriculture, National Agricultural Statistical Service 2007 Census of Agriculture, accessed September 27, 2010, at http://www.agcensus.usda.gov/Publications/2007/ Online_Highlights/Ag_Atlas_Maps/Farms/). reactions with solid-phase $\mathrm{OC}, \mathrm{Fe}$, and(or) $\mathrm{S}$, which are relatively plentiful, but in finite supply in the aquifer materials.

Although some DOC is present in recharging water, patterns in DOC concentrations indicate that it has limited reactivity at most ACT sites. $\mathrm{As} \mathrm{O}_{2}$ and $\mathrm{NO}_{3}{ }^{-}$are consumed, concentrations of DOC remain relatively constant at Maryland, Washington, and California (fig. 5). At Nebraska, a decrease in DOC concentration does occur, suggesting some involvement of DOC in the redox reactions; however, the total amount of DOC supplied in recharging water is too small to account for the amount of $\mathrm{O}_{2}$ reduction and denitrification observed at this site (fig. 4). Characterization of the specific ultraviolet absorbance (SUVA) of DOC gives an indication of its reactivity or labile fraction (Weishaar and others, 2003). The SUVA analyses at these sites suggest that there are no substantial differences in DOC reactivity in aerobic versus anaerobic groundwater (fig. 5). The DOC in recharging water at these sites appears not to play a major role in $\mathrm{O}_{2}$ reduction or denitrification.

The dependence of denitrification on solid-phase reductants in the aquifer has implications for the long-term sustainability of $\mathrm{NO}_{3}{ }^{-}$natural attenuation. In many agricultural areas, the concentration of $\mathrm{NO}_{3}{ }^{-}$in deep soils and shallow groundwater has greatly increased since the mid 1900 's as a result of increased fertilizer use. The vertical velocities of water, $\mathrm{NO}_{3}^{-}$, and $\mathrm{O}_{2}$ have also increased because of groundwater pumping and irrigation, as well as changes in land cover and tillage (fig. 6). At the ACT sites and others with moderate rates of denitrification and $\mathrm{O}_{2}$ reduction, the increased fluxes of $\mathrm{O}_{2}$ and $\mathrm{NO}_{3}{ }^{-}$result in deeper penetration of $\mathrm{NO}_{3}{ }^{-}$, especially around high-production wells pumped for irrigation or for domestic water use. The increased fluxes of $\mathrm{O}_{2}$ and $\mathrm{NO}_{3}{ }^{-}$result in faster consumption of the finite reductants from the solid phase. As the most reactive solid phase reductants become depleted in the aquifer, denitrification rates in those sediments will probably decrease, resulting in further $\mathrm{NO}_{3}{ }^{-}$transport to deeper groundwater and surface water bodies.

\section{Implications for Future Nitrate Fluxes and Water Quality}

These results show that with current agricultural practice, the depletion of aquifer reductants will result in decreased rates of denitrification. The timing of this 


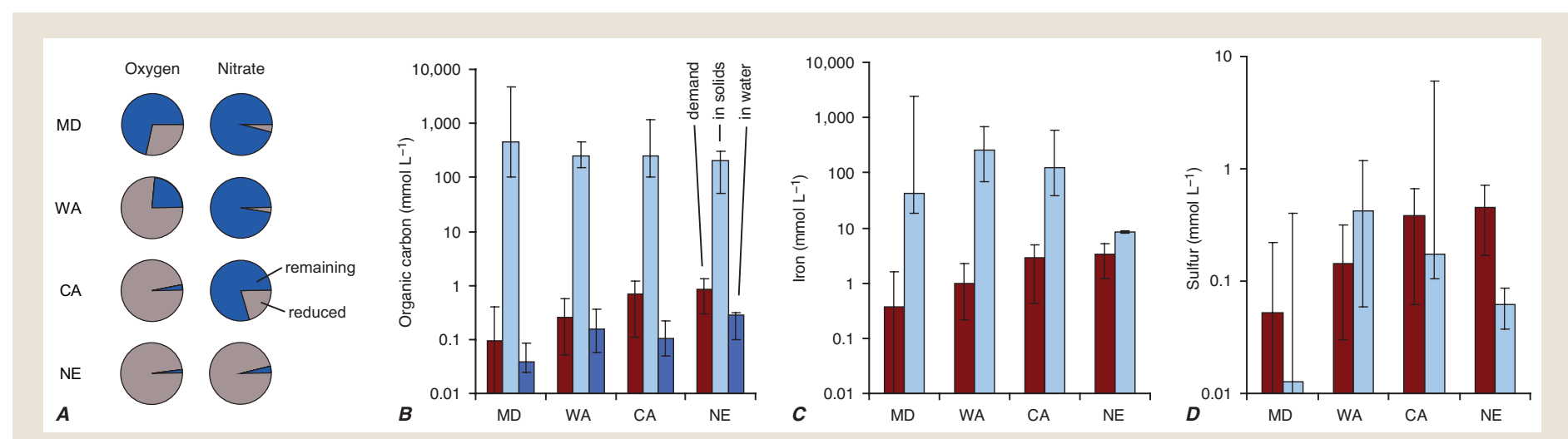

Figure 4. Data on redox reactions from the four study sites in Maryland (MD), Washington (WA), California (CA), and Nebraska (NE). A, Pie charts show the fraction of $\mathrm{O}_{2}$ and $\mathrm{NO}_{3}{ }^{-}$that have reacted with reductants, as well as the fraction remaining in groundwater. The amount of reduced $\mathrm{O}_{2}$ and $\mathrm{NO}_{3}{ }^{-}$corresponds to a "demand," defined as the amount of a reductant needed to cause the observed extent of reactions. Possible reductants include (B) organic carbon, (C) reduced iron, and (D) reduced sulfur; $\mathrm{mmol}^{-1}$, millimoles per liter. On the bar charts, the dark red bars show the median demand for each reductant at each site. Light blue bars show the median amount of each reductant present in solid aquifer materials. Dark blue bars show the median amount of a reductant in recharging water at the water table (greater than $0.01 \mathrm{mmol}^{-1}$ for organic carbon only). The lines above and below the tops of the bars show the minimum and maximum values. Observed quantities of solid iron and organic carbon were adequate at every site to explain the measured reduction of $\mathrm{O}_{2}$ and $\mathrm{NO}_{3}{ }^{-}$, whereas sulfur was sufficient at some sites. Dissolved reductants were not sufficient to account for the measured reduction of $\mathrm{O}_{2}$ and $\mathrm{NO}_{3}{ }^{-}$at any site, implying that reactions with solid-phase organic carbon, iron, and(or) sulfur are responsible for $\mathrm{O}_{2}$ reduction and denitrification at these sites.

response, however, is uncertain. Of the total quantity of reductants identified in the ACT studies, a portion will not react because of physical sequestration or chemical recalcitrance. Previous studies have shown that a large fraction of the total solid-phase reductants are nonreactive on the time scales over which contaminant transport occurs (van Helvoort and others, 2007). Furthermore, although solid $\mathrm{OC}$ and $\mathrm{Fe}$ are plentiful relative to $\mathrm{S}$, previous studies have often found preferential reactivity of S over OC (for example, Postma and others, 1991; van Helvoort and others, 2007). At the ACT sites, preferential reactivity of the Fe and $\mathrm{S}$ mineral phases is supported by higher ratios of $\mathrm{Fe} / \mathrm{OC}$ and $\mathrm{S} /$ $\mathrm{OC}$ in reduced zones of the aquifer relative to aerobic zones, where these reductants have been depleted. This suggests that the sustainability of denitrification depends on a relatively small reactive fraction of solidphase reductants, especially the minerals containing Fe and S. Existing studies show that the relative abundance and reactivity of the various solid-phase reductants can vary widely, depending on depth, grain size, and duration of exposure of sediments to the atmosphere during and after deposition (Hartog and others, 2002, 2005). Improved understanding of the sustainability of denitrification will require additional information about the reactivity of these heterogeneously distributed aquifer reductants.

The importance of the rates and sustainability of denitrification varies
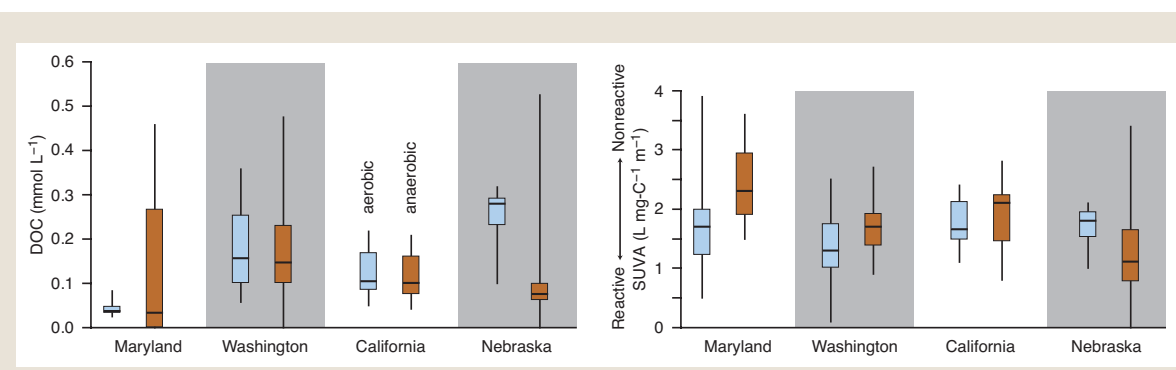

Figure 5. Comparisons of dissolved organic carbon (DOC) concentrations and specific ultraviolet absorbance (SUVA) in aerobic zones $\left(O_{2}>1 \mathrm{mmol} \mathrm{L}^{-1}\right)$ versus anaerobic zones $\left(O_{2}<1 \mathrm{mmol} \mathrm{L}^{-1}\right)$. Units: $\mathrm{mmol} \mathrm{L}^{-1}$, millimoles per liter; $L \mathrm{mg}-\mathrm{C}^{-1} \mathrm{~m}^{-1}$, liters per milligram carbon per meter; SUVA is defined as the UV absorbance at 254 nanometers measured in inverse meters $\left(\mathrm{m}^{-1}\right)$ divided by the DOC concentration measured in milligrams of carbon per liter (mg-C $L^{-1}$ ). Vertical lines connect the minimum and maximum values, boxes show the interquartile range (containing the 50 percent of samples closest to the median), and horizontal lines inside the boxes show the median. The concentration of DOC does not change substantially las shown by overlapping interquartiles) between aerobic and anaerobic zones at the Maryland, Washington, and California sites. At the Nebraska site, DOC in anerobic waters is less concentrated, which suggests $\mathrm{O}_{2}$ reduction has consumed some DOC. However, reactivity of DOC as indicated by SUVA does not change substantially at any of the sites. Also, as shown in figure 4, total quantities of DOC in recharge are insufficient to account for the measured reduction of $\mathrm{O}_{2}$ and $\mathrm{NO}_{3}{ }^{-}$. Overall, these results indicate that involvement of $\mathrm{DOC}$ as a reductant of $\mathrm{O}_{2}$ is limited.

depending on local site conditions. Rates of denitrification are similar among the ACT study sites and are typically low (Green and others, 2008a; Green and others, 2009). At sites with relatively high rates of recharge, such as Maryland, Washington, and California (Green and others, 2008b), denitrification is too slow to substantially affect oxidant and reductant concentrations during transport through shallow groundwater. Declines in denitrification will likely produce minor changes relative to the large total flux through shallow groundwater. At sites such as Nebraska, where recharge rates are variable, or Mississippi (another ACT site currently being studied), where recharge rates are low (Green and others, 2009), declines in denitrification rates or increased $\mathrm{NO}_{3}{ }^{-}$ flux will likely cause dramatic increases of $\mathrm{NO}_{3}{ }^{-}$fluxes to deeper groundwater and adjacent water bodies. Because denitrification rates are low at all of the ACT sites, sustaining potable groundwater quality will require long-term efforts to optimize the efficient use of nitrogen fertilizers and irrigation.

Although this study focuses on $\mathrm{NO}_{3}{ }^{-}$, the results apply to other groundwater contaminants affected by redox geochemistry. For example, the increased fluxes of $\mathrm{O}_{2}$ and $\mathrm{NO}_{3}{ }^{-}$from agriculture can result in release of metals such as arsenic and uranium bound in mineral reductants (Böhlke, 2002; Izbicki and others, 2008) and may facilitate transport of these redox-sensitive solutes by oxidizing portions of the aquifer that would otherwise reduce the solutes to immobile forms. 


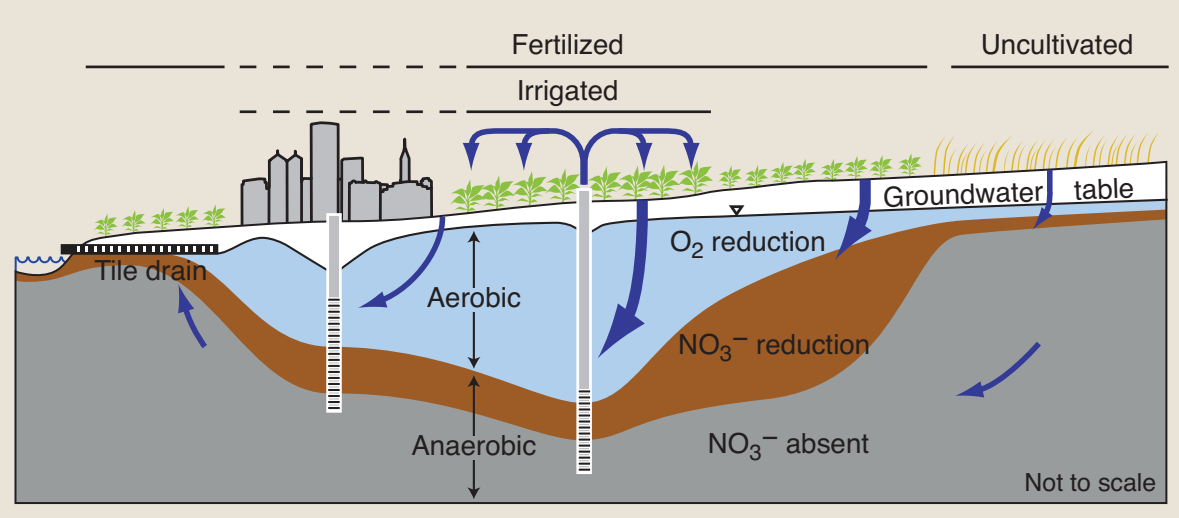

Figure 6. Schematic diagram showing the changing fluxes of water, dissolved oxygen $\left(\mathrm{O}_{2}\right)$, and nitrate $\left(\mathrm{NO}_{3}{ }^{-}\right)$caused by increased agricultural applications of fertilizer and groundwater extraction. The thickness of arrows indicates the concentration of oxidants $\left(\mathrm{NO}_{3}{ }^{-}\right.$and $\left.\mathrm{O}_{2}\right)$, and their length indicates the velocity of transport. Comparison with the unaltered landscape at the right (and figure 2) shows how the zones of $\mathrm{O}_{2}$ and $\mathrm{NO}_{3}{ }^{-}$reduction extend deeper in the aquifer around large production wells, under fertilized fields, and especially under fields that are both fertilized and irrigated. The zones of reduction may occur very close to the groundwater table in locations where groundwater discharge and(or) tile drains prevent downward migration of oxidant-rich groundwater.

\section{Conclusions}

Results of this research to date justify the following conclusions:

- $\mathrm{NO}_{3}{ }^{-}$contamination is prevalent in groundwater at the studied agricultural sites.

- Denitrification in these aquifers relies on a finite reservoir of solid-phase reductants.

- Because of increased fluxes of $\mathrm{O}_{2}$ and $\mathrm{NO}_{3}{ }^{-}$beneath agricultural lands, this finite reservoir of solid-phase reductants is being depleted.

- Further work is needed to quantify the existing reduction capacity and to determine the long-term sustainability of $\mathrm{NO}_{3}{ }^{-}$natural attenuation in agricultural aquifers.

\section{References}

Böhlke, J.K., 2002, Groundwater recharge and agricultural contamination: Hydrogeology Journal, v. 10, no. 3, p. 438-439.

Capel, P.D., Hamilton, P.A., and Erwin, M.L., 2004, Studies by the U.S. Geological Survey on sources, transport, and fate of agricultural chemicals: U.S. Geological Survey Fact Sheet 2004-3098, 4 p.

Dubrovsky, N.M., Burow, K.R., Clark, G.M., Gronberg, J.M., Hamilton P.A., Hitt, K.J., Mueller, D.K., Munn, M.D., Nolan, B.T., Puckett, L.J., Rupert, M.G., Short, T.M., Spahr, N.E., Sprague, L.A., and Wilber, W.G., 2010, The quality of our Nation's waters - nutrients in the Nation's streams and groundwater, 1992-2004: U.S. Geological Survey
Circular 1350, 174 p. (Also available at http://pubs.usgs.gov/circ/1350/.)

Green, C.T., Puckett, L.J., Böhlke, J.K., Bekins, B.A., Phillips, S.P., Kauffman, L.J., Denver, J.M., and Johnson, H.M., 2008a, Limited occurrence of denitrification in four shallow aquifers in agricultural areas of the United States: Journal of Environmental Quality, v. 37, no. 3, p. 994-1009.

Green, C.T., Fisher, L.H., and Bekins, B.A., 2008b, Nitrogen fluxes through unsaturated zones in five agricultural settings across the United States: Journal of Environmental Quality, v. 37, no. 3, p. 1073-1085.

Green, C.T., Welch, H., and Coupe, R., 2009, Multi-tracer analysis of vertical nitrate fluxes in the Mississippi River Valley alluvial aquifer: Eos (American Geophysical Union Transactions), v. 90, Fall meeting supplement, abs. H31C0799.

Hartog, N., Griffioen, J., and Van der Weijden, C.H., 2002, Distribution and reactivity of $\mathrm{O}_{2}$-reducing components in sediments from a layered aquifer: Environmental Science and Technology, v. 36, no. 11, p. 2338-2344.

Hartog, N., Griffioen, J., and van Bergen, P.F., 2005, Depositional and paleohydrogeological controls on the distribution of organic matter and other reactive reductants in aquifer sediments: Chemical Geology, v. 216, nos. 1-2, p. 113-131.

Howarth, R.W., and Marino, R., 2006, Nitrogen as the limiting nutrient for eutrophication in coastal marine ecosys- tems; evolving views over three decades: Limnology and Oceanography, v. 51, p. 364-376.

Izbicki, J.A., Stamos, C.L., Metzger, L.F., Halford, K.J., Kulp, T.R., and Bennett, G.L., 2008, Source, distribution, and management of arsenic in water from wells, eastern San Joaquin ground-water subbasin, California: U.S. Geological Survey Open-File Report 2008-1272, 8 p.

Nolan, B.T., and Stoner, J.D., 2000, Nutrients in groundwaters of the coterminous United States, 1992-1995: Environmental Science and Technology, v. 34, p. 1156-1165.

Postma, D., Boesen, C., Kristiansen, H., and Larsen, F., 1991, Nitrate reduction in an unconfined aquifer; water chemistry, reduction processes, and geochemical modeling: Water Resources Research, v. 27, p. 2027-2045.

van Helvoort, P.J., Griffioen, J., and Hartog, N., 2007, Characterization of the reactivity of riverine heterogeneous sediments using a facies-based approach; the Rhine-Meuse delta (the Netherlands): Applied Geochemistry, v. 22, no. 12, p. 2735-2757.

Weishaar J.L., Aiken, G.R., Bergamaschi, B.A., Fram, M.S., Fujii, R., and Mopper, K., 2003, Evaluation of specific ultraviolet absorbance as an indicator of the chemical composition and reactivity of dissolved organic carbon: Environmental Science and Technology, v. 37, p. 4702-4708.

World Health Organization, 2004, Guidelines for drinking-water quality (3rd ed.), v. 1. Recommendations: Geneva, World Health Organization, 515 p.

Christopher T. Green and Barbara A. Bekins Edited by Peter H. Stauffer

Graphic design by Darlene A. Ryan

For more information please contact:

Christopher T. Green (650) 329-4728

ctgreen@usgs.gov

Paul Capel, Agricultural Chemicals Team Leader (612) 625-3082 capel@usgs.gov

See also USGS fact sheets about individual agricultural chemical studies:

Maryland: http://pubs.usgs.gov/fs/fs08003

California: http://pubs.usgs.gov/fs/fs08103

Washington: http://pubs.usgs.gov/fs/fs08203

Nebraska: http://pubs.usgs.gov/fs/fs08303

This Fact Sheet and any updates to it are available online at:

http://pubs.usgs.gov/fs/2010/3077/ 